Res., Soc. Dev. 2019; 8(5):e30851008

ISSN 2525-3409 | DOI: http://dx.doi.org/10.33448/rsd-v8i5.1008

\title{
Proposta Pedagógica para a Educação Infantil: Uma necessidade contemporânea
}

Pedagogical Proposal for Early Childhood Education: A Contemporary Need

Propuesta Pedagógica para la Educación Infantil: Una necesidad contemporánea

Diana Machado

ORCID: https://orcid.org/0000-0003-1556-0468 Universidade do Vale do Taquari - UNIVATES, Brasil

E-mail: dyanamachado@ hotmail.com

Daiana Graciele Bueno

ORCID: https://orcid.org/0000-0001-6173-0822

Universidade do Vale do Taquari - UNIVATES, Brasil

E-mail: daiana.bueno@universo.univates.br

Sabrina Monteiro

ORCID: https://orcid.org/0000-0001-7883-9728

Universidade do Vale do Taquari - UNIVATES, Brasil

E-mail: sabrinamonteiro1991@gmail.com

Recebido: 25/02/2019 | Revisado: 25/02/2019 | Aceito: 04/03/2019 | Publicado: 06/03/2019

\section{Resumo}

Esse relato de experiência tem como objetivo discutir sobre o processo de elaboração e aplicação do Projeto Político Pedagógico (PPP) nas Escolas de Educação Infantil de um município no interior do Rio Grande do Sul, Brasil. Esta é uma pesquisa qualitativa e teve duas etapas, sendo a primeira com início em 2015, quando a referida escola iniciou a (re)construção do Projeto Político Pedagógico e a segunda em 2017, após o desenvolvimento e aplicação do mesmo. Como resultado da investigação inferiu-se que: a participação integral e coletiva dos protagonistas da educação, a mobilização da comunidade escolar e o compromisso do profissional permitem a superação dos desafios recorrentes na (re)construção do Projeto Político-Pedagógico, considerando a importância, vitalidade e as concepções norteadoras do trabalho a ser desenvolvido na instituição de ensino.

Palavras-chave: Educação Infantil; Re(construção); Projeto Político Pedagógico. 


\section{Abstract}

This experience report aims to discuss the process of elaboration and application of the Pedagogical Political Project (PPP) in Child Education Schools of a municipality in the interior of Rio Grande do Sul, Brazil. This is a qualitative research and had two stages, the first one to begin in 2015, when the said school began the reconstruction of the Political Pedagogical Project and the second in 2017, after the development and application of it. As a result of the research it was inferred that: the integral and collective participation of the protagonists of education, the mobilization of the school community and the commitment of the professional allow the overcoming of the recurring challenges in the (re) construction of the Political-Pedagogical Project, considering the importance, vitality and the guiding conceptions of the work to be developed in the educational institution.

Keywords: Early Childhood Education; Reconstruction; Political Pedagogical Project.

\section{Resumen}

Este relato de experiencia tiene como objetivo discutir sobre el proceso de elaboración y aplicación del Proyecto Político Pedagógico (PPP) en las Escuelas de Educación Infantil de un municipio en el interior de Rio Grande do Sul, Brasil. Esta es una investigación cualitativa y tuvo dos etapas, siendo la primera con inicio en 2015, cuando la referida escuela inició la reconstrucción del Proyecto Político Pedagógico y la segunda en 2017, después del desarrollo y aplicación del mismo. Como resultado de la investigación se infería que: la participación integral y colectiva de los protagonistas de la educación, la movilización de la comunidad escolar y el compromiso del profesional permiten la superación de los desafíos recurrentes en la (re) construcción del Proyecto Político-Pedagógico, considerando la importancia, vitalidad y las concepciones orientadoras del trabajo a ser desarrollado en la institución de enseñanza.

Palabras clave: Educación infantil; Re (construcción); Proyecto Político Pedagógico.

\section{Introdução}

A superação dos desafios na educação está interligada ao compromisso coletivo da elaboração da Proposta Pedagógica das Instituições de Ensino. Participar de uma construção ou (re)construção de um projeto nesta amplitude exige comprometimento, tanto pedagógico como político, confrontando com as diferentes realidades e o desejo de que tal documento se efetive concretamente, buscando a constante melhoria educacional. 
Para tanto, neste artigo discute-se sobre o processo de elaboração e aplicação do Projeto Político Pedagógico (PPP) nas Escolas de Educação Infantil de um município no interior do Rio Grande do Sul, Brasil. A escolha não foi ao acaso, mas sim pela autora fazer parte desta instituição, estar presente nesta (re)construção como professora atuante e na aplicação e desenvolvimento da proposta como gestora. A inquietude dos docentes perante a escrita do PPP levou a reflexão de elicitar os desafios e superações de acordo com a visão individual de cada um dos educadores (recreacionista, monitores e professores) que fizeram parte deste universo.

Partindo dessa acepção, Maia e Costa (2013) evidenciam que um trabalho com esta dimensão exige dedicação, tempo, compromisso pedagógico e político de todos os envolvidos no processo. Assim como, a importância de desenvolver a visão democrática, mesmo diante dos percalços comuns neste tipo de trabalho, já que a definição de intenções, a identificação e análise das dificuldades, o apontamento de metas e os objetivos comuns são exercícios árduos e complexos.

Durante o processo de (re)construção do Projeto Político Pedagógico na Educação Infantil, foram surgindo diversos questionamentos entre os educadores, desde quais os maiores desafios encontrados até como a escola vem atualmente desenvolvendo o trabalho pedagógico. Por meio destas inquietações, a pesquisa foi ocupando seu espaço, com o intuito de refletir, discutir e estudar cada uma delas, para poder de alguma forma contribuir no processo de elaboração de uma Proposta Pedagógica preocupada com a integralidade e aprendizagem do aluno.

Partindo destas perturbações que originaram este artigo, inicialmente fez-se uma contextualização e apresentação do objetivo deste estudo. Em seguida, disserta-se sobre princípios norteadores referentes à elaboração de um Projeto Político Pedagógico e uma reflexão contextualizada na Educação Infantil, partindo do pressuposto de que as creches e pré-escolas existentes já vinham organizando o seu trabalho considerando além do cuidar o educar, mesmo que de forma pouco sistemática, porém recentemente a Educação Infantil foi reconhecida na legislação com caráter educativo. Após, apresenta-se a metodologia abordada e também a análise dos dados obtidas. Por fim, são apresentadas as considerações finais, destacando a importância do processo de pesquisa e a busca na qualidade do trabalho desenvolvido na Educação Infantil, contribuindo para o avanço de reflexões e para produção de novos conhecimentos. 


\section{Caminhos e descaminhos do Projeto Político Pedagógico contextualizado no Ensino Infantil}

Pensar em uma educação na contemporaneidade é pensar nos descaminhos da educação. É refletir como aquilo que já vem encaminhado por um longo período, porém que precisa ser repensado em possibilidades de progresso no ensino. As propostas pedagógicas nesta perspectiva vêm como um grande desafio, que vem tomando novos rumos e discussões, dando espaço à reflexão e viabilização de propostas e práticas pedagógicas interessadas nos alunos como parte do processo, que viabilizem um ensino para a aprendizagem de qualidade, pensando na integralidade do ser.

Na década de 1970 a classe trabalhadora através de sindicatos e associações buscava a retomada da identidade cidadã. Estes momentos foram significativos para que, posteriormente, na década de 1980, se iniciasse o novo período democrático com debates e discussões sobre o papel político da educação e de sua democratização, em prol de um ensino de qualidade para todos, gerando a necessidade de se estabelecer novas políticas e diretrizes para a educação e consequentemente a construção dos Projetos Políticos Pedagógicos (MAIA E COSTA, 2013).

A Lei de Diretrizes e Bases (LDB) em 1996, vem para reafirmar a importância das comunidades escolares elaborarem os seus Projetos Políticos Pedagógicos, tendo por finalidade a formação comum e igualitária, atendendo as necessidades dos contextos históricos, culturais de cada realidade. Até aqui parece claro qual é intencionalidade de elaborar uma Proposta Pedagógica. Mas por que tal ação é um desafio? São muitos os autores que abordam o assunto, elucidando princípios e concepções norteadoras, etapas, estruturação, apontando caminhos para a elaboração de tal proposta. E por que tal ação é ainda mais desafiante quando pensada para a Educação Infantil?

Com estas inquietações que buscou-se compreender tal processo de reconstrução e de execução de um Projeto Político Pedagógico em uma Escola de Educação Infantil. Mas antes de apresentar a pesquisa propriamente, é preciso refletir sobre o Ensino Infantil no contexto educacional e histórico, visto que a Educação Infantil passou a fazer parte da Educação Básica recentemente. Por um longo período não se discutia sobre a infância, ou seja, ser criança não era uma garantia de se ter infância. Não havia a preocupação em relação a sua formação 
Res., Soc. Dev. 2019; 8(5):e30851008

ISSN 2525-3409 | DOI: http://dx.doi.org/10.33448/rsd-v8i5.1008

integral enquanto sujeito. Ao longo da história até os dias atuais diferentes concepções e entendimentos em relação à infância e à criança foram sendo apresentadas, discutidas.

Nesta perspectiva, percebe-se a criança como protagonista, levando em consideração de que o período de 0 a 5 anos é um dos momentos mais importantes e significativos do desenvolvimento humano, coadunando com as afirmações de Redin (2007, p.17):

A criança é um ser que dá sentido ao mundo em que vivi, fazendo diferentes leituras das tramas sociais. Tem, portanto, no decorrer da vida, não só a possibilidade de aprender como também de contribuir para a constituição de um novo momento histórico social, feito da diversidade cultural e da singularidade dos sujeitos.

Do mesmo modo, enaltecendo a criança, Salles e Farias complementam (2013, p. 56) que:

Considerar a criança como um sujeito é levar em conta, nas relações em que com ela estabelecemos, que ela tem desejos, ideias, opiniões, capacidade de decidir, de criar, de inventar, que se manifestam desde cedo, nos seus movimentos, nas suas expressões, no seu olhar, nas suas vocalizações, na sua fala.

Assim, nesta fase da infância, considerando a criança como um sujeito sócio-histórico e cultural, cidadão de direitos, sentiu-se a necessidade de se pensar na contribuição ao desenvolvimento pleno dos seus primeiros anos de vida. Dessa forma, as Diretrizes Curriculares Nacionais da Educação Básica (2013, p.81) apontam que:

[...] um novo paradigma do atendimento à infância - iniciado em 1959 com a Declaração Universal dos Direitos da Criança e do Adolescente e instituído no país pelo artigo 227 da Constituição Federal de 1988 e pelo Estatuto da Criança e do Adolescente (Lei 8.069/90) - tornou-se referência para os movimentos sociais de "luta por creche" e orientou a transição do entendimento da creche e pré-escola como um favor aos socialmente menos favorecidos para a compreensão desses espaços como um direito de todas as crianças à educação, independentemente de seu grupo social.

À vista disso, passa-se a reconhecer a Educação Infantil como dever do estado com a educação deste nível. A LDB regulamenta a integração das creches e pré-escolas nos sistemas de ensino como a primeira etapa da Educação Básica, considerando que: “[...] tem como finalidade o desenvolvimento integral da criança de até 5 (cinco) anos, em seus aspectos físico, psicológico, intelectual e social, complementando a ação da família e da comunidade" (BRASIL, 1996, art. 29).

A partir destas considerações sobre o Ensino Infantil que surge a importância de se pensar num Projeto Político Pedagógico que vê a criança como sujeito participante, ativo, curioso, capaz de construir conhecimento a partir de suas vivências e experiências, pois a 
criança foi se tornando um sujeito de direitos, com características que a difere das pessoas em outras fases da vida. Barbosa e Horn (2008, p. 28) evidenciam ao citar que: “[...] as crianças são capazes de criar teorias, interpretações, perguntas, e são coprotagonistas na construção dos processos de conhecimento".

Neste sentido é necessária a explicitação de concepções norteadoras, princípios, intenções e formas de organização do trabalho pedagógico para a consolidação da identidade de uma instituição de Educação Infantil. Pensar nas concepções norteadoras de uma Proposta Pedagógica significa refletir e explicitar uma visão de sociedade, de ser humano, de criança, de desenvolvimento e aprendizagem, de educação e de cuidado. O momento da elaboração do PPP constitui a oportunidade de discutir, de fundamentar teoricamente e legalmente as ações pretendidas.

Veiga (2004, p.11) apud Maia e Costa (2013, p.23) destaca as seguintes características que um Projeto Político Pedagógico deve apresentar em sua concepção:

\footnotetext{
Ser processo participativo de decisões;

Preocupar-se em instaurar uma forma de organização de trabalho pedagógico que desvele os conflitos e as contradições;

Explicitar princípios baseados na autonomia da escola, na solidariedade entre os agentes educativos e no estímulo à participação de todos no projeto comum e coletivo;

Conter opções explícitas na direção de superar problemas no decorrer do trabalho educativo para uma realidade específica;

Explicitar o compromisso com a formação do cidadão.
}

Partindo das concepções pressupostas sobre o Projeto Político Pedagógico, Salles e Farias (2013), considerando o contexto da Educação Infantil, acrescentam que a articulação entre fundamentação teórica e o contexto sócio-histórico e cultural possibilita definição de objetivos e orienta a organização de todos os elementos da prática de cuidar e educar. E com todos estes princípios norteadores elencados pelos autores surge o grande desafio das escolas de Educação Infantil, de como colocar no papel e o mais importante, executar uma proposta pedagógica que tenha por finalidade contribuir na formação de sujeitos mais sustentáveis, humanitários, justos, democráticos e capazes de transformar o mundo.

\section{3. (Re)construção do Projeto Político Pedagógico na Educação Infantil: Desafios?} Superações? Possibilidades? 
Esta pesquisa teve caráter qualitativo, na qual primou inicialmente por um estudo do referencial teórico para subsidiar a investigação e coleta de dados. Foram apresentadas considerações teóricas sobre a (re)construção de um Projeto Político Pedagógico, contemplando os princípios históricos, norteadores e legais, seguido de uma contextualização deste processo na Educação Infantil.

A partir disso, realizou-se a primeira coleta de dados, através de um questionário com os docentes de uma Escola Municipal de Educação Infantil no interior do Rio Grande do Sul, Brasil, no ano de 2015. Foram enviados 14 questionários, através de e-mail, obtendo-se a devolução de todos. O questionário continha perguntas que inicialmente referiam-se sobre a formação, função e o tempo de atuação na Educação Infantil. Após, perguntava-se para relatar sobre os desafios e superações na (re)construção do Projeto Político Pedagógico. E ao final, uma avaliação sobre a participação na elaboração.

A segunda coleta de dados se deu no ano de 2017 através de um questionário com os docentes que fazem parte atualmente da mesma Escola e estavam desenvolvendo esta Proposta Pedagógica desde o início do ano letivo de 2016. Foram enviados 17 questionários, obtendo-se a devolução 16 questionários. As questões abordadas em ambos deram conta da formação dos profissionais, tempo de atuação na educação, participação na elaboração da Proposta Pedagógica, desafios e superações no decorrer do processo, avaliando o desempenho pessoal e coletivo, assim como se deu a aplicação desta proposta através da prática pedagógica de sala de aula ou conforme função que desempenha no educandário.

É importante destacar que até então, a escola na qual se realizou a pesquisa vinha desenvolvendo a sua Prática Pedagógica baseada nos estudos das Linguagens Geradoras do autor Gabriel Junqueira (2013), que resultou após anos de estudo no livro: "Proposta Político Pedagógica das Escolas Municipais de Educação Infantil de Lajeado”. Porém este estudo e reelaboração das Propostas Pedagógicas das Escolas Municipais Infantis, foi uma solicitação da Secretaria Municipal de Educação, que se efetivou a partir da Conferência Municipal de Educação de Lajeado. Iniciou-se uma caminhada de pesquisas, reflexões, estudos e debates, com a finalidade de construir um documento que além de apresentar a realidade da instituição, também norteasse o trabalho realizado na mesma.

Através dos questionários enviados aos docentes foi possível constatar que no ano de 2015 a escola disponibilizava de uma diretora, uma supervisora pedagógica, quatro 


\section{Res., Soc. Dev. 2019; 8(5):e30851008 \\ ISSN 2525-3409 | DOI: http://dx.doi.org/10.33448/rsd-v8i5.1008}

professoras, sete monitoras e uma recreacionista, lotadas de acordo com suas funções nas turmas atendidas pela escola: Berçário (uma professora e 3 monitoras), Turma A (Uma professora e 1 monitora, 1 recreacionista, 1 estagiária), Turma B (uma professora e uma monitora), Turma $\mathrm{C}$ (uma professora e uma monitora). Todas as docentes eram formadas na área da Educação, em Nível Médio - Modalidade Curso Normal. Do total 3 cursavam o Ensino Superior, 1 era formada em Nível Superior, 6 eram Pós-Graduadas, 1 cursando mestrado. Em relação ao tempo de atuação das docentes na educação variam de 1 ano a 20 anos, e na referida Escola de Educação Infantil constatou-se que o tempo de docência é de menos de 1 ano a 9 anos.

Todas as docentes afirmaram ter participação da (re)construção do Projeto PolíticoPedagógico. A maioria participou ativamente, justificando a importância de sentir-se parte deste, de participar dos estudos, decisões, reflexões, reuniões e palestras, já que esta construção é uma ação democrática, e os profissionais são coprotagonistas deste processo. Duas educadoras participaram parcialmente, uma estava afastada do educandário por um determinado período e outra por desinteresse referente ao grupos de estudos.

Questionadas referente aos desafios durante a (re)construção do Projeto Político Pedagógico destacou-se alguns apontamentos apresentados pelas educadoras ${ }^{1}$, que possibilita uma reflexão sobre este processo:

\footnotetext{
“Dúvidas em relação a estrutura do documento”. (E 7)

“Divergências de opiniões”. (E 2)

"Definições de ações em comum acordo”. (E 1)

"O curto prazo de tempo para a entrega do documento final à Secretaria de Educação”. (E 3)

"O reconstruir a partir de concepções já estabelecidas, o inovar, formulação de conceitos conforme a realidade da qual a escola está inserida”. (E 9)

"Desafios relacionados ao processo de construção do PPP: desacomodação, mobilização, desafios no sentido positivo”. (E 11)
}

Já quanto aos desafios:
"Novos conhecimentos, redigir um texto com autonomia de acordo com a realidade e concepções da EMEI”. (E 10)
"Os debates e divergências de ideias que levaram a uma construção positiva”. (E 4)
“Cumprir os prazos estabelecidos pela Secretaria de Educação”. (E 3)
"A superação do medo do desconhecido, do novo, cooperação, construção coletiva, coleguismo, diálogos, mudanças”. (E 10)
"Participação da comunidade escolar, organização de grupos de estudos”. (E 6)
“A escrita final do PPP”. (E 5)

\footnotetext{
${ }^{1}$ Com a finalidade de manter o caráter ético, não se fará menção aos nomes das educadoras, sendo que estas serão identificados com a letra E precedido com um número qualquer.
} 
Ao analisar os desafios e superações elencadas pelas educadoras, percebeu-se que os profissionais da educação têm procurado compreender o que vem a ser o Projeto Político Pedagógico, sua função e importância na implementação e consolidação de tal documento, que os desafios sempre estiveram presentes durante esta elaboração, mas que eles são possíveis de superação. Em suas escritas, consideraram a satisfação em fazer parte deste processo de (re)construção, a oportunidade de representar através do documento os seus anseios, desejos, o fazer pedagógico, a relação entre prática e a teoria, o destaque para a criança como protagonista, o conhecimento aperfeiçoado referente a infância, a criança, destacando que o Projeto Político Pedagógico ficou coerente com a realidade da qual a escola está inserida e o trabalho dos educadores. Foram relatos de satisfação, podendo destacar que um desafio elucidado por todas educadoras foi o curto prazo de tempo que a escola tinha para apresentar o documento, porém procurou encontrar alternativas para realizar este estudo.

Assim como foi destaque o envolvimento pleno, o comprometimento com os grupos de estudos, o entusiasmo e respeito mútuo, a colaboração de acordo com os conhecimentos, experiências. A maioria referiu-se ao coletivo por parte das docentes, e uma minoria ao coletivo no âmbito de toda a comunidade escolar, ou seja, a participação das famílias se resumiu a um questionário inicial. Este foi um dos pontos que me despertou interesse, ao mesmo tempo que me inquieta, e me questiono: será que é o suficiente? De que outra forma as famílias, funcionários, alunos poderiam estar participando desta proposta?

Para complementar esta reflexão acredita-se importante citar os representativos da escola como o Conselho Escolar que é o "[...] órgão representativo da comunidade escolar, de natureza deliberativa, consultiva, avaliativa e fiscalizadora, sobre a realização do trabalho pedagógico e administrativo da instituição escolar e em conformidade com as políticas e diretrizes educacionais" (MAIA e COSTA, 2013, p. 86). Também a Associação de Pais, Mestres e Funcionários que tem por responsabilidade “[...] a organização e a interação dos segmentos da sociedade organizada no contexto escolar, discutindo a política educacional, visando sempre a melhoria do processo pedagógico e administrativo da comunidade escolar" (MAIA e COSTA, 2013, p. 89).

Fica explícito a importância da participação de todos os envolvidos na comunidade escolar na concretização do coletivo com a finalidade de construção ativa e crítica, em um processo democrático, de permanentes reflexões e de discussões dos problemas escolares. Contudo, após esta análise e a elucidação dos dados coletados no ano de 2015, surge o 
interesse em aprofundar este estudo, após os educadores terem a oportunidade de aplicação de tal proposta pedagógica, podendo correlacionar as informações coletadas em dois momentos diferenciados. A inquietação primordial foi a curiosidade de como se deu a prática desta proposta e como a escola está organizada atualmente considerando a proposta pedagógica.

Sendo assim através do questionário enviado no ano de 2017 foi possível constatar que o quadro de docentes e suas respectivas formações tiveram poucas alterações. A escola disponibiliza de uma diretora, uma supervisora pedagógica, quatro professoras, oito monitoras, uma recreacionista e três estagiárias lotadas de acordo com suas funções nas turmas atendidas pela escola: Berçário (1 professora, 1 recreacionista e 2 monitoras), Turma A (1 professora e 3 monitoras), Turma B/C (1 professora, 2 monitoras e 1 estagiária), Turma D/E (1 professora e 1 monitora). As nomenclaturas das duas últimas turmas tiveram alteração. Apenas uma docente não é formada na área da Educação, em Nível Médio - Modalidade Curso Normal. A maioria tem formação em Nível Superior, e um número considerável em Nível de Pós Graduação. Em relação ao tempo de atuação das docentes na educação variam de 1 ano a 22 anos, e na referida Escola de Educação Infantil constatou-se que o tempo de docência é de menos de 1 ano a 11 anos.

Dentre o retorno obtido das docentes, 8 disseram participar ativamente da reelaboração do Proposta Pedagógica em 2015, 1 parcialmente e 7 não participaram, pois não faziam parte do educandário no ano de reestudo, porém todas tiveram acesso ao Projeto Político Pedagógico que fica disponibilizado para pesquisa, leitura, estudo, assim como informaram realização de uma formação pedagógica no início do ano letivo, na qual o assunto foi a abordagem e estudo da Proposta Pedagógica da referida escola.

Foi interessante analisar cada uma das avaliações das docentes, que independente da função que desempenha e da intensidade de participação de reconstrução de tal proposta, expressaram principalmente suas angústias. É possível aqui recapitular as impressões de 2015, onde era a nítida a satisfação por tal documento, que ainda estava apenas no papel, mas que no ano seguinte foi se configurando, ou desconfigurando na prática de sala de aula. Os registros escritos se mostraram como desafio quase que unânime, visto que as educadoras elencaram que alguns aspectos precisam ser revistos. Algumas educadoras foram além, comparando e diferenciando o documento com a prática pedagógica, para elas a prática não está coerente com a proposta abordada no projeto, porém a prática tem mais qualidade do que a organização pedagógica do papel, e foi através desta discussão que a escola decidiu 
reestudar o Proposta Pedagógica, sendo que neste ano de 2017 novos estudos foram iniciados, grupos de estudos.

Através desta pesquisa, percebeu-se que as primeiras impressões de que pensar em Proposta Pedagógica para Educação Infantil é um desafio contemporâneo, é refletir em como organizar, planejar o trabalho pedagógico, político, social da escola, considerando o coletivo, sujeitos, tempos e espaços. Ao mesmo tempo que vislumbre-se possibilidades de que é possível as Escolas de Educação Infantil apresentarem propostas consistentes. Foi possível diagnosticar que a escola compreendeu que o Projeto Político Pedagógico não é documento estagnado, que precisa ser revisitado, reestudado, repensando. E ainda ficam alguns desafios, algumas inquietações, algumas angustias e necessidades de posteriores estudos que efetivem uma participação mais democrática, uma participação não só de educadores, mas de comunidade escolar e todos os seus pares.

\section{Considerações Finais}

$\mathrm{Na}$ (re)construção de um Projeto Político Pedagógico faz parte do processo esclarecer objetivos e linhas de ações para alcançar uma educação de qualidade, na busca por uma transformação social. Assim ele deve estar relacionado aos interesses da comunidade escolar. Nesta perspectiva ele passa a ser um instrumento de gestão, de compromisso político e pedagógico coletivo. Através dele há a possibilidade de abordar questões administrativas, pedagógicas, financeiras, políticas e as ações que garantem as funções da escola. Partindo dessa premissa, acredita-se que o objetivo da pesquisa tenha sido alcançado, uma vez que discutir sobre o processo de elaboração e aplicação do Projeto Político Pedagógico (PPP) nas Escolas de Educação Infantil é algo que merece cada vez maior atenção.

Considerando a Educação Infantil uma conquista recente no âmbito educacional, vislumbrar as escolas empenhadas na elaboração de um Projeto Político-Pedagógico demonstra a primeira superação no desafio de mobilização para tal processo. A Escola Infantil escolhida para a pesquisa não omitiu assim como enumerou os desafios que um trabalho nesta amplitude requer, mas estes foram usados a favor da instituição, foi uma base para iniciar uma sequência de superações, que resultou num documento digno de uma comunidade escolar participativa, que está preocupada não apenas em ter um local para deixar as crianças, mas 
sim um local chamado de escola, um local que vai contribuir na formação de sujeitos críticos, humanitários, cidadãos capazes de transformações sociais.

É importante destacar que após a escrita do documento estar finalizada e a aplicação desta proposta, a escola percebeu que ainda era necessário mais estudo, que a proposta escrita estava se distanciando da prática, que precisavam de reformulações, de continuidade no processo de reelaboração. Neste contexto pode-se afirmar a importância de reavaliar uma proposta já estabelecida, avaliando avanços/superações, dificuldades/desafios. E um dos grandes desafios é convencer a comunidade escolar (docentes, educandos, pais e/ou responsáveis, representantes da comunidade local) na participação da ação coletiva e na construção deste documento, podendo ser destacado como um dos desafios principais a ser superado pela instituição escolar.

Assim, a direção e a coordenação pedagógica da escola devem assumir o papel de mediadores entre grupo de docentes, funcionários, alunos e pais, articulando o processo de organização, construção, discussões da proposta política pedagógica, assim como prestar assistência aos envolvidos e fortalecimento do trabalho coletivo. Os docentes por sua vez, também são peças fundamentais e protagonistas neste processo democrático, aliados aos gestores e coordenadores, na função de assumir com comprometimento estudos, diálogos, intermediações, ações críticas e democráticas. Para Maia e Costa (2013) o professor precisa articular o entorno trazendo-o para dentro do contexto escolar com seus aspectos econômicos, políticos e culturais. Também compete a sua função orientar a comunidade escolar na construção de um processo pedagógico na perspectiva democrática de forma a garantir o processo coletivo de reflexão-ação.

Contudo, inferiu-se com a escrita deste artigo que os desafios são constantes na elaboração de um documento como o Projeto Político Pedagógico e que a construção coletiva precisa ser uma das superações da Educação Infantil. Fica o desejo de retornar a este educandário para um novo estudo a partir desta pesquisa, sabendo que reformulações e novos estudos estão sendo realizados.

\section{Referências}


Barbosa, M. C. S. Horn, M. da G. S. Projetos Pedagógicos na Educação Infantil. Porto Alegre: Artmed, 2008.

Brasil. (2001). Ministério da Educação. Conselho Nacional de Educação. Diretrizes Nacionais para Educação Especial na Educação Básica. Brasília: MEC, Secretaria da Educação Especial.

Brasil. (1996). Ministério da Educação. Lei de diretrizes e Bases da Educação. Brasília, MEC. Disponível em: http://www.planalto.gov.br/ccivil_03/Leis/L9394.htm. Acesso em 14 de Nov. de 2015.

Brasil. (1998). Ministério da Educação e do Desporto. Secretaria de Educação Fundamental. Referencial Curricular Nacional para a Educação Infantil. Brasília: MEC/SEF.

Maia, B. P. Costa, M. T. de A. (2013). Os desafios e superações na construção coletiva do Projeto Político-Pedagógico. $1^{\mathrm{a}}$ ed. Curitiba: InterSaberes.

Mallmann, C. I., et al. (2011). Proposta político - pedagógica das escolas municipais de educação infantil de Lajeado- RS. Ed. Univates.

Redin, E. Redin, M. M. Müller, F. (2007) Infâncias: cidades e escolas amigas das crianças. Porto Alegre: Mediação.

Rodrigues, A. C. da S. (2008). Pesquisa: A formação do professor- pesquisador. Pesquisa: In: $O$ aluno da Educação infantil e dos anos iniciais. Obra organizada pela Universidade Luterana do Brasil(ULBRA). Curitiba: IBPEX.

Salles. F. Faria. V. (2012). Currículo na Educação Infantil: diálogo com os demais elementos da Proposta Pedagógica. $2^{\mathrm{a}}$ ed. São Paulo: Ática.

\title{
Porcentagem de contribuição de cada autor no manuscrito
}

\author{
Diana Machado - $100 \%$ \\ Daiana Graciele Bueno - 100\% \\ Sabrina Monteiro - $100 \%$
}


ISSN 2525-3409 | DOI: http://dx.doi.org/10.33448/rsd-v8i5.1008 